\title{
The Differences Between Multifocal and Unifocal Papillary Thyroid Carcinoma in Unilateral Lobe: A Meta-Analysis
}

\author{
Ting Zhang, Liang He, Zhihong Wang, Wenwu Dong, Wei Sun, Ping Zhang \\ and Hao Zhang*
}

Department of Thyroid Surgery, The First Hospital of China Medical University, Shenyang, China

Background: As many inconsistent reports on the clinical manifestations and prognosis between unilateral unifocal PTC (UUPTC) and unilateral multifocal PTC (UMPTC),

OPEN ACCESS

Edited by:

Jan Baptist Vermorken,

University of Antwerp, Belgium

Reviewed by:

Maria Cossu Rocca,

European Institute of Oncology (IEO),

Ashok R. Shaha,

Memorial Sloan Kettering Cancer

Center, United States

${ }^{*}$ Correspondence:

Hao Zhang

haozhang@cmu.edu.cn

Specialty section: This article was submitted to Head and Neck Cancer, a section of the journal

Frontiers in Oncology

Received: 22 January 2021

Accepted: 27 August 2021

Published: 16 September 2021

Citation:

Zhang T, He L, Wang Z, Dong W, Sun $W$, Zhang $P$ and Zhang $H$ (2021) The Differences Between Multifocal and Unifocal Papillary Thyroid Carcinoma in Unilateral Lobe: A Meta-Analysis. Front. Oncol. 11:657237. doi: 10.3389/fonc.2021.657237 identifying the difference should guide management. The purpose of this study was to investigate other additional differences between UUPTC and UMPTC in addition to their difference in the number of cancer foci.

Data Sources: A systematic literature search was conducted in the PubMed and Web of Science databases for relevant studies published before December 31, 2020. Their reference lists were also reviewed.

Review Methods: Two reviewers independently extracted data and assessed the quality of eligible studies. Studies on patients who underwent an open thyroidectomy with or without neck dissection were included. Data were analyzed using the RevMan 5.3 software.

Results: Fifteen studies comprising 9,665 patients were selected for the meta-analysis. UMPTC occurred in $10 \%$ to $36 \%$ of all PTC cases. There were no significant differences between UMPTC and UUPTC patients in age, gender, tumor size, and extrathyroidal extension (ETE). However, significant differences $(P<0.05)$ between UMPTC and UUPTC patients were observed in central lymph node metastasis (CLNM), lateral lymph node metastasis (LLNM), tumor-node-metastasis (TNM) stage I+II, TNM stage III+IV, the recurrence/persistence of the UMPTC group after total thyroidectomy and overall recurrence/persistence.

Conclusion: UMPTC patients are more likely to have CLNM, LLNM, more advanced TNM stage, and recurrence/persistence than UUPTC patients. Compared with UUPTC, UMPTC patients should undergo central lymph node dissection, and pay more attention to LLNM, TNM stage and recurrence/persistence during the follow-up.

Keywords: unilateral unifocal PTC, unilateral multifocal PTC, central lymph node metastasis, lateral lymph node metastasis, tumor-node-metastasis stage, recurrence/persistence 


\section{INTRODUCTION}

Papillary thyroid carcinoma (PTC) is the most common endocrine malignancy (1). It is categorized into unilateral PTC and bilateral PTC based on tumor location and into unifocal PTC and multifocal PTC based on the number of cancer foci. Multifocality is a common pathological feature of PTC. However, the prevalence of multifocality is significantly lower than that of unifocality in the unilateral lobe. To date, the etiology of multifocal thyroid cancer remains unclear.

There have been many different basic research reports on the occurrence of multifocal PTC in recent years, some believed to be of polyclonal origin $(2,3)$, but others considered to be intraglandular spread $(4,5)$. It is postulated that the clinical manifestations of bilateral PTC are worse than unilateral PTC. The bilateral PTC has multiple cancer foci, easy extrathyroidal extension (ETE) (6), uncomplicated cervical lymph node metastasis, easy recurrence, and poor prognosis after the operation (7). Cognizant of this, radical resection treatment is needed, followed by a close follow-up after surgery. However, there are different treatment opinions for unilateral PTC. Unilateral unifocal PTC (UUPTC) can be surgically ablated (8) though some scholars choose to carry out active surveillance (9). Both the American Thyroid Association (ATA) and the National Comprehensive Cancer Network (NCCN) recommend total surgical thyroidectomy for unilateral multifocal PTC (UMPTC) $(10,11)$.

Nonetheless, there are many inconsistent reports on the clinical manifestations and prognosis between UUPTC and UMPTC.

Some studies postulate that the prognosis of UMPTC is poor (12), whereas others suggest that UMPTC has good prognosis as UUPTC because they are differentiated thyroid carcinoma (13, 14). Herein, a meta-analysis was performed to investigate the differences between multifocal and unifocal PTC in the unilateral lobe.

\section{MATERIALS AND METHODS}

This meta-analysis was carried out following the Preferred Reporting Items for Systematic Reviews and Meta-analysis (PRISMA) guidelines (15).

\section{Search Strategy}

A systematic literature search of relevant studies published before December 31, 2020, was performed in the PubMed and Web of Science databases. The key words included (( (thyroid cancer OR thyroid carcinoma) AND papillary) OR PTC) AND [(Multifocal OR Multiple OR Multinodular) AND (Unifocal OR Solitary OR Single) AND (Unilateral OR one side lobe)]. Two authors (Zhang $\mathrm{T}$ and Sun $\mathrm{W}$ ) conducted the selection process independently. All discrepancies were resolved through discussions and consensus by the two authors or referred to a third author.

\section{Selection Criteria}

Prospective or retrospective studies published in English and whose participants were primary PTC patients who underwent thyroid and lymphadenectomy surgery were included in the meta-analysis. The included studies had their participants diagnosed through intraoperative or postoperative pathology. Moreover, the studies had extractable demographics and clinical data for thyroidectomy patients. However, review articles, conference abstracts, editorials, letters, and single case reports were excluded. Duplicate studies and those with no reported outcomes were also excluded.

\section{Data Extraction and Quality Assessment}

Relevant data from the included articles were extracted independently by the two investigators following a standardized format. The data included the first author's name, year of publication, country of origin, research design, number of cases, potential risk factors, and other corresponding data (Figure 1). The potential risk factors included age, gender, extrathyroidal extension (ETE), central lymph node metastasis (CLNM), lateral lymph node metastasis (LLNM), and the tumornode-metastasis (TNM) stage and recurrence/persistence. The Newcastle-Ottawa quality assessment scale was used to assess the quality of the studies (16).

\section{Data Analysis}

Data analysis was performed using Review Manager version 5.3 (Cochrane Collaborative, Oxford, United Kingdom), and results presented as the mean difference IV (MD) or odds ratios (ORs) with a $95 \%$ confidence interval (CI). A P-value of less than 0.05 indicated that there was a statistical significance of the observed difference. Heterogeneity of the data was quantified using the $Q$ test and $\mathrm{I}^{2}$ statistics, while that among studies was estimated using Cochran's Q statistic (17). The fixed-effects model was used when $\mathrm{P}>0.10$ and $\mathrm{I}^{2}<50 \%$; otherwise, a random-effects model was applied. The potential publication bias was evaluated using Begg's funnel plot.

\section{RESULTS}

The search strategy generated 2226 potentially relevant studies for meta-analysis. Figure $\mathbf{1}$ is a flowchart detailing the studies retrieved and excluded. After removing studies that did not meet the inclusion criteria, 15 studies $(7,14,18-30)$ comprised of 9665 patients were selected for analysis. Amongst the studies, the incidence of multifocal and unifocal PTC was $10 \%-36 \%$ and $63 \%-90 \%$, respectively. The incidences of all the studies are summarized in Table 1.

\section{Age}

Seven studies were included in the analysis of differences between UMPTC and UUPTC patients based on age. There were no significant differences between the UMPTC and UUPTC patients based on age $(\mathrm{MD}=-.018,95 \% \mathrm{CI}=-2.78-2.42, \mathrm{P}=$ 0.89) (Figure 2A).

\section{Gender}

Six studies were included in the analysis of the differences between UMPTC and UUPTC patients based on gender (male 


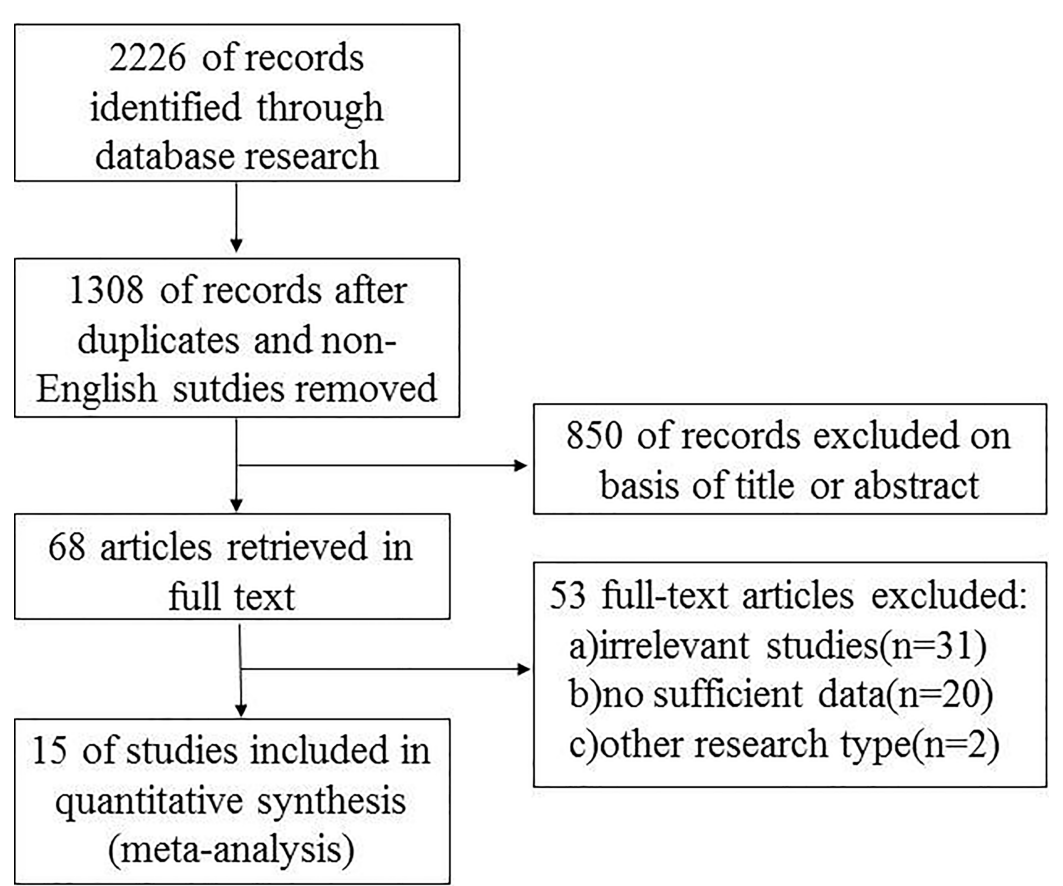

FIGURE 1 | Flowchart of study selection.

TABLE 1 | Characteristics of eligible studies.

\begin{tabular}{|c|c|c|c|c|c|c|}
\hline \multirow[t]{2}{*}{ Author } & \multirow[t]{2}{*}{ Year } & \multirow[t]{2}{*}{ Country } & \multirow[t]{2}{*}{ Study design } & \multicolumn{2}{|c|}{ Case number } & \multirow[t]{2}{*}{ Quality score } \\
\hline & & & & Multifocal & Unifocal & \\
\hline Kalliopi Pazaitou-Panayiotou & 2008 & Greece & retrospective analysis & 10 & 44 & 6 \\
\hline Y. C. Lim & 2009 & korea & retrospective analysis & 9 & 77 & 7 \\
\hline Hye Jeong Kim & 2013 & korea & retrospective analysis & 193 & 1423 & 9 \\
\hline Qunzi Zhao & 2013 & china & retrospective analysis & 23 & 140 & 8 \\
\hline XIAOLONG LI & 2013 & china & retrospective analysis & 35 & 312 & 8 \\
\hline Ayham Al Afif MSc & 2015 & Canada & retrospective analysis & 46 & 85 & 8 \\
\hline Kuk-Jin Kim & 2015 & korea & retrospective analysis & 821 & 1488 & 9 \\
\hline Abbas Ali Tam & 2016 & Turkey & retrospective analysis & 121 & 604 & 8 \\
\hline Ning Qu & 2016 & china & retrospective analysis & 78 & 287 & 8 \\
\hline Weibin Wang & 2016 & china & retrospective analysis & 211 & 1517 & 9 \\
\hline Hai-Jiang Qu & 2017 & china & retrospective analysis & 111 & 302 & 8 \\
\hline Tinghai Xiang & 2018 & china & retrospective analysis & 40 & 147 & 7 \\
\hline Krzysztof Kaliszewski & 2019 & Poland & retrospective analysis & 48 & 114 & 7 \\
\hline Yossi Geron & 2019 & Israel & retrospective analysis & 156 & 505 & 8 \\
\hline Victoria Harries & 2020 & USA & retrospective analysis & 230 & 619 & 9 \\
\hline
\end{tabular}

and female). There were no significant differences in the number of male and female patients between the two groups (male, $\mathrm{OR}=$ $1.13,95 \% \mathrm{CI}=0.98-1.31, \mathrm{p}=0.09$; female, $\mathrm{OR}=0.57,95 \% \mathrm{CI}=$ $0.25-1.28, \mathrm{p}=0.17$ ) (Figures 2B, C).

\section{Tumor Size}

Five studies were included in this analysis. There were no significant differences in the primary tumor size between UMPTC and UUPTC patients (OR $=0,95 \%$ CI $=-0.26-0.26$, $\mathrm{p}=0.99)$ (Figure 3A).

\section{Incidences of ETE}

This analysis included seven studies. There were no significant differences in ETE incidences between UMPTC and UUPTC patients $(\mathrm{OR}=1.51,95 \% \mathrm{CI}=0.99-2.30, \mathrm{P}=0.05)($ Figure 3B$)$.

\section{Incidences of CLNM}

Thirteen studies were included in the analysis of differences between UMPTC and UUPTC patients based on CLNM. There were significant differences in CLNM incidences between the two groups. The UMPTC group had higher incidences of CLNM 

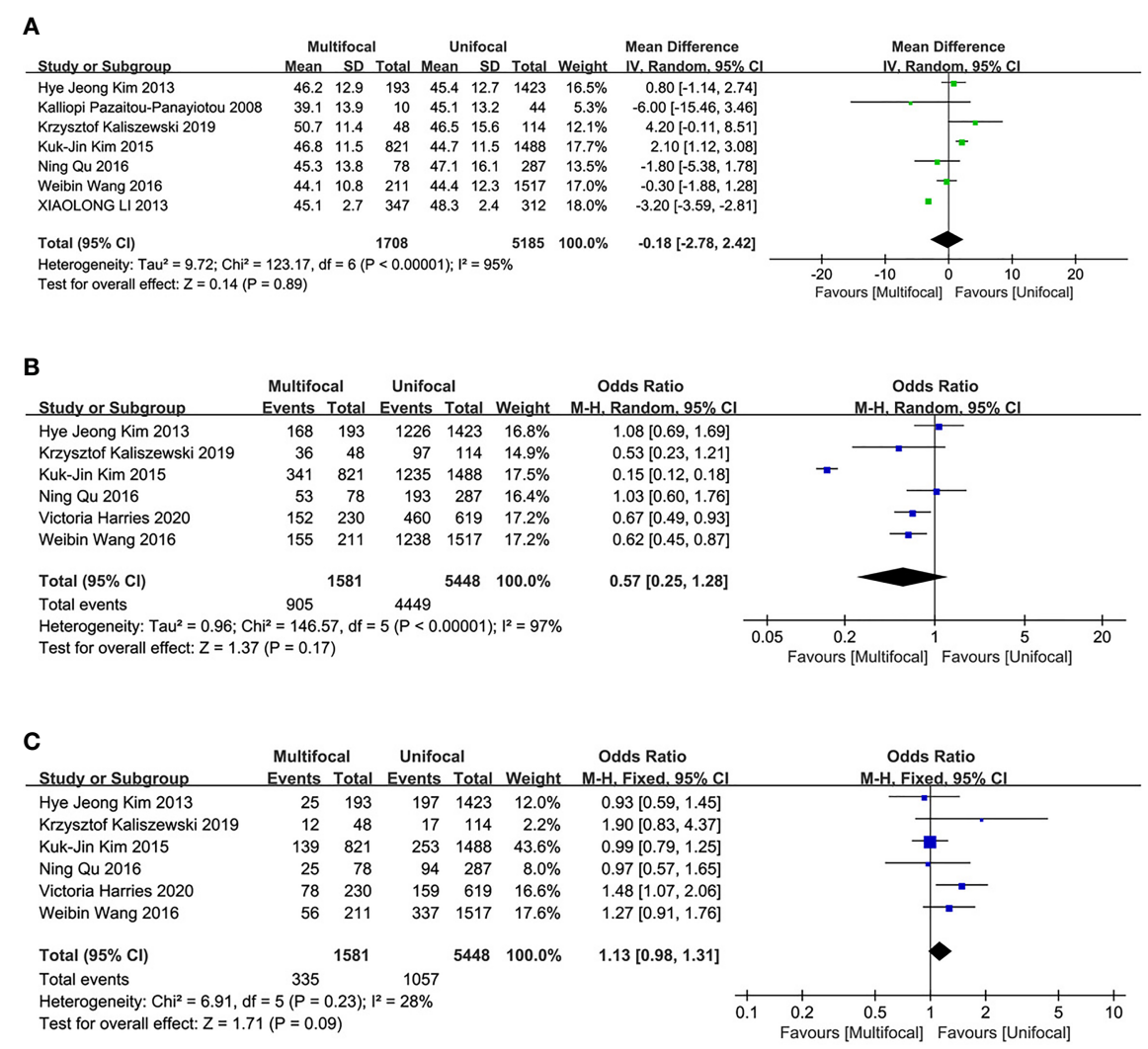

FIGURE 2 | Meta-analysis results for the difference between the UMPTC and UUPTC. (A) Age; (B) Female; (C) Male.

than the UUPTC group $(\mathrm{OR}=1.77,95 \% \mathrm{CI}=1.42-2.21, \mathrm{P}<$ 0.00001) (Figure 3C).

\section{Incidences of LLNM}

This analysis included three studies. LLNM incidences were significantly different between the two groups. The UMPTC group had higher incidences of LLNM than the UUPTC group $(\mathrm{OR}=1.65,95 \% \mathrm{CI}=1.15-2.35, \mathrm{p}=0.006)($ Figure 4A).

\section{TNM Stage}

The analysis included four studies. The UMPTC group exhibited significantly less TNM stage I+II than the UUPTC group (OR = $0.60,95 \%$ CI $=0.48-0.75, \mathrm{P}<0.00001$ ) (Figure 4B). However, it exhibited significantly higher TNM stage III+IV than the UUPTC group $(\mathrm{OR}=1.55,95 \% \mathrm{CI}=1.21-1.99, \mathrm{p}=$ 0.0005) (Figure 4C).

\section{Recurrence/Persistence of PTC}

The overall recurrence/persistence of PTC was assessed in seven studies. The UMPTC group had a higher incidence of overall PTC recurrence/persistence compared to the UUPTC group $(\mathrm{OR}=2.32,95 \% \mathrm{CI}=1.79-3.00, \mathrm{P}<0.00001)($ Figure 5A $)$. Analysis of PTC recurrence/persistence between the two groups after total thyroidectomy revealed that the UMPTC group had a significantly higher recurrence/persistence than the UUPTC group $(\mathrm{OR}=2.27,95 \% \mathrm{CI}=1.71-3.02, \mathrm{P}<0.00001)$ (Figure 5B). Six studies were included in this analysis.

\section{DISCUSSION}

Studies hypothesize that multifocality in PTC results from intrathyroidal metastasis from the primary tumor or the coexistence of separate neoplastic foci $(31,32)$. Testing the latter hypothesis revealed that BRAFV600E mutation is a risk factor for PTC multifocality (33). In the same line, the clinical and prognostic implications of multifocality $v s$. unifocality for PTC patients are still controversial. This study is the first metaanalysis to explore the difference between UMPTC and UUPTC patients.

Several studies postulate that some clinicopathological features are different between UMPTC and UUPTC, including age, gender, tumor size, and ETE. Qu N et al. (7) reported that an increase in tumor foci during diagnosis was strongly associated with older age. Similarly, Emine Ozlem Gur found out that the tumor size of the multifocal group was significantly larger than that of the unifocal group in a study that comprised 305 PTC patients (34). It is also postulated that females have higher incidences of UMPTC compared to males (35). A retrospective analysis involving 2,095 PTC patients reported that multifocal 


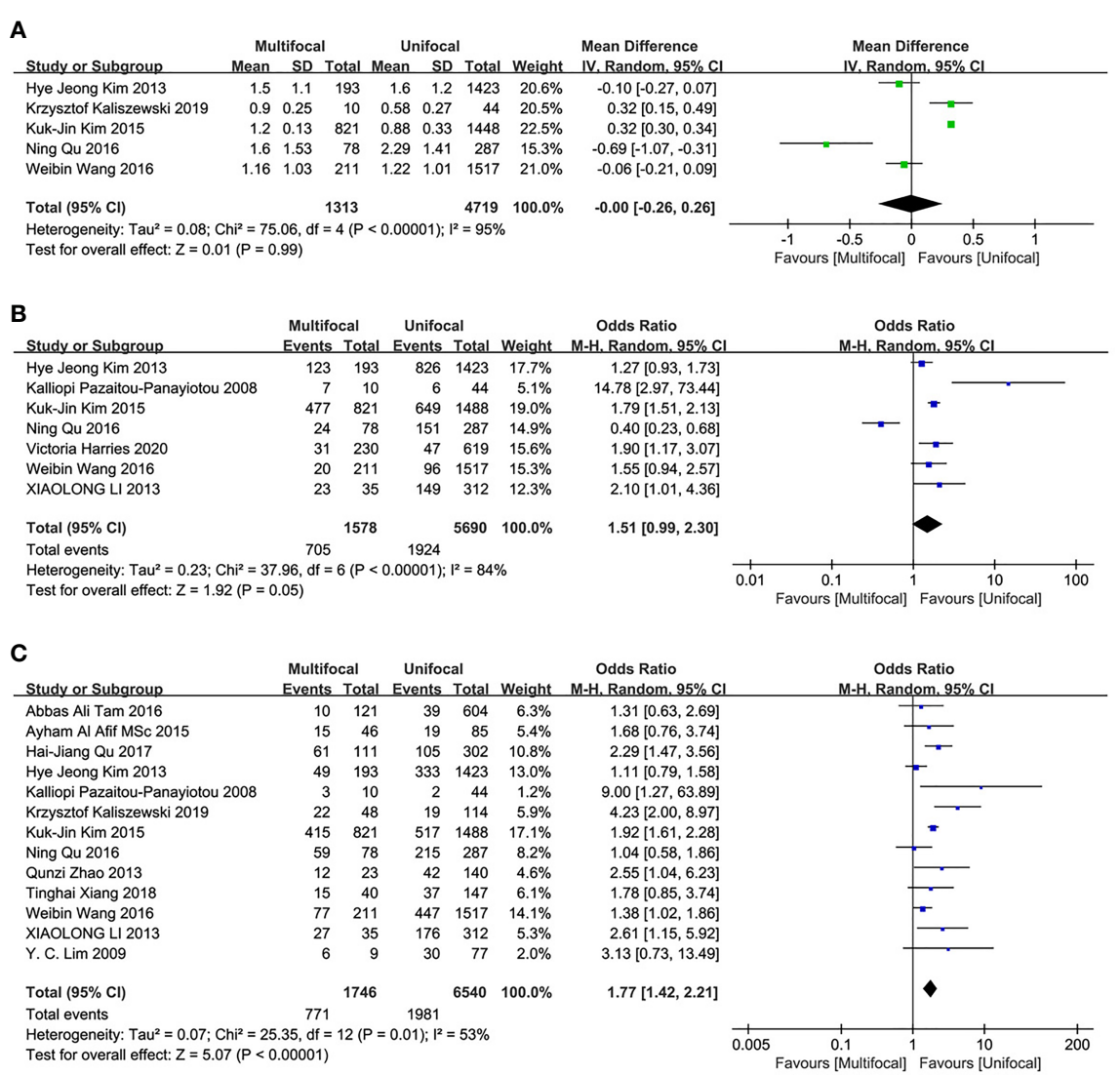

FIGURE 3 | Meta-analysis results for the difference between the UMPTC and UUPTC. (A) Size; (B) ETE; (C) CLNM.

tumors (32\% of cases) had a significantly higher ETE incidence than unifocal tumors (20). However, other studies report that the tumor characteristics of UMPTC and UUPTC are similar $(36,37)$.

The association between CLNM and LLNM with UMPTC and UUPTC remains controversial. Some studies postulate that multifocality is not independently associated with CLNM (38). However, many studies have focused on the risk factors of CLNM and LLNM for UMPTC patients. For example, Zheng WH suggests that multifocality should be assessed when selecting patients for prophylactic central neck lymph node dissection (39). Multivariate analysis by Luca Sessa and Yoon Kyoung So revealed that multifocality is an independent risk factor for CLNM and LLNM (40,41). Besides, tumor classification was standardized using the TNM stage system of the American Joint Committee on Cancer. The TNM stage system is used to stage thyroid cancers. It can then be used in combination with patient characteristics to define likely prognosis (42). Although most TNM stage systems do not include PTC multifocality, many endocrine surgeons regard it as an important factor in patient treatment. Kim et al. reported that an increase in tumor foci was strongly associated with the advanced TNM stage of PTC. The advanced TNM stage is significantly more frequent in UMPTC than in UUPTC (43).
Li Genpeng et al. reported that patients with multifocal PTC had a more advanced TNM stage (44).

In the 2015 update of the ATA guidelines, multifocality was not regarded as a risk factor in the three-tiered categorical risk of recurrence system. Some studies report that PTC patients have recurrent cases despite the general thought that PTC has an excellent prognosis. Previous studies have contradicting opinions about whether the recurrence/persistence of PTC is different between UMPTC and UUPTC. Recently, a multicentered study comprised of a large cohort demonstrated that tumor multifocality lacks an independent risk prognostic value in clinical outcomes of UMPTC (45). However, some studies report that UMPTC patients have a higher risk of recurrence/ persistence than UUPTC patients $(46,47)$.

In our study, there were no significant differences in age, gender, size, and ETE between the UMPTC and UUPTC patients, which was inconsistent with these published results, these results may have been caused by differences in the selection criteria and different study designs. However, our analysis showed UMPTC patients were more likely to have CLNM, LLNM and advanced TNM stage during diagnosis compared to UUPTC patients. The possible reason is that UMPTC is associated with tumor aggressiveness, and UMPTC plays an important role in tumorigenesis and development. 
A

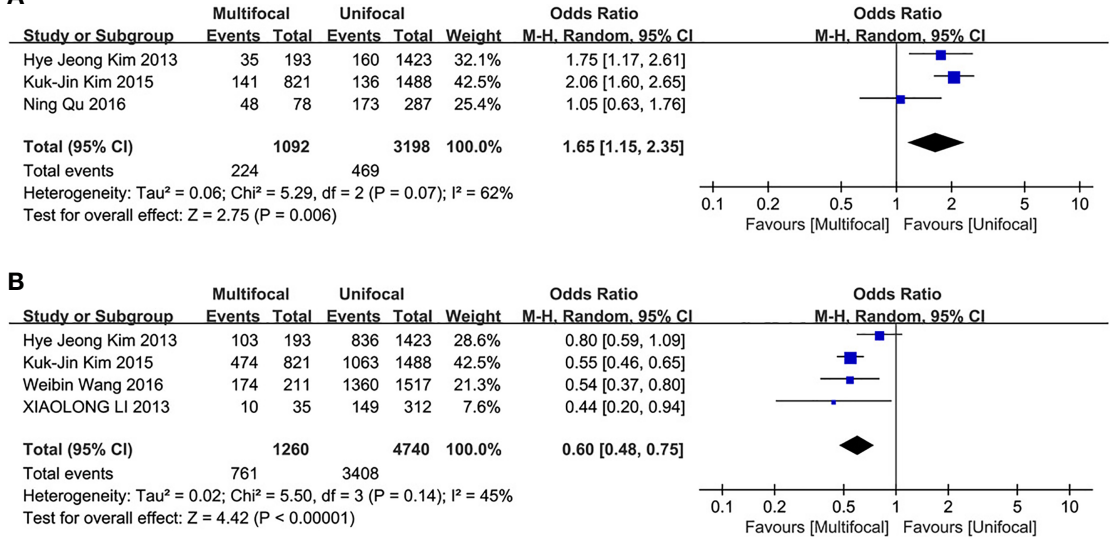

C

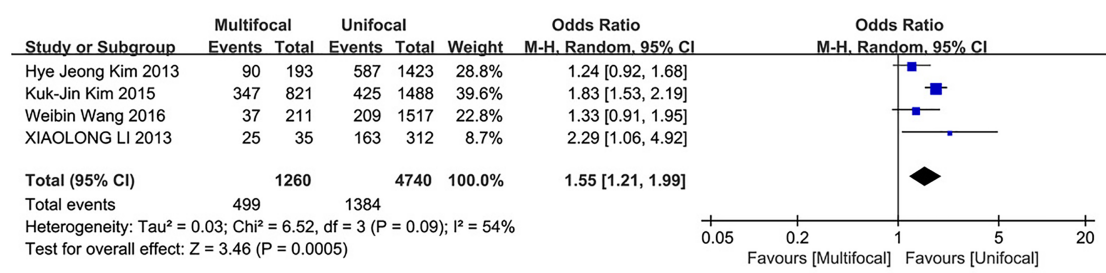

FIGURE 4 | Meta-analysis results for the difference between the UMPTC and UUPTC. (A) LLNM; (B) TNM stage I+II; (C) TNM stage III+IV.

Clinical recurrences/persistence included local recurrence/ persistence, contralateral residual lobe, the cervical lymph nodes, and distant metastasis. The operative methods of overall recurrence/persistence rate included total thyroidectomy, near- total thyroidectomy, hemithyroidectomy, and subtotal thyroidectomy. The recurrence/persistence of total thyroidectomy between UMPTC and UUPTC was further analyzed to eliminate the interference of other operative methods on the overall
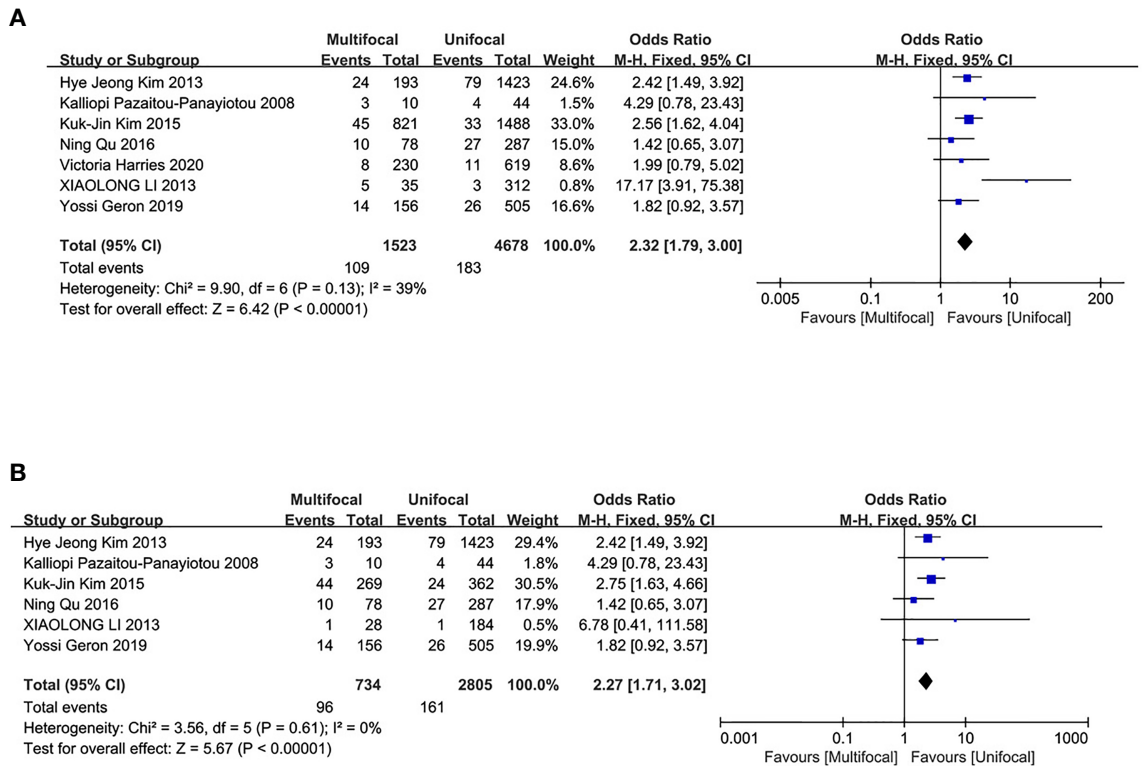

FIGURE 5 | Meta-analysis results for the difference between the UMPTC and UUPTC. (A) Overall recurrence/persistence; (B) The recurrence/persistence after total thyroidectomy. 
recurrence/persistence of the contralateral remnant lobe. Differences in recurrence/persistence of total thyroidectomy were found to be similar to the overall recurrence. The recurrence/ persistence of UMPTC after total thyroidectomy was higher than UUPTC. A forest map analysis of recurrence/persistence after other operative methods was not made because of inadequate information. Nonetheless, regardless of the surgical extent, UMPTC is more likely to have recurrence/persistence than UUPTC. Consequently, clinicians need to employ more aggressive initial treatment and closer follow-up for patients with UMPTC. Herein, it was concluded that UMPTC patients have a higher incidence rate of overall recurrence/persistence than UUPTC patients.

Despite the significant positive findings, this study was limited by several factors. The number of studies included was small because of the unavailability of raw data from some articles. Moreover, most of the patients in the included studies were from Asia, which may cause bias if the findings are applied in all races. There was no randomized controlled trial included in this study. In the same line, this meta-analysis included several large studies that could have introduced some bias in general study outcomes. The types of patients that underwent thyroidectomy for thyroid lesions were inconsistent, including total thyroidectomy, subtotal thyroidectomy, and lobectomy plus isthmus. Besides, differences in the study populations and aims of the included studies might have led to selective bias. Only the number of patients with or without recurrence/persistence were counted without distinguishing the site of recurrence/ persistence, ipsilateral or bilateral, synchronous or metachronous, and single or multiple time/site recurrence. Lateral cervical nodes were dissected only in patients suspected of having lymph node metastasis based on clinical or radiologic examinations in most of the studies. Patients who had not undergone LLN dissection were regarded as LLN negative. Therefore, the rate of LLNM might have been underestimated.

\section{REFERENCES}

1. Rasheed MRHA, Xu B. Molecular Alterations in Thyroid Carcinoma. Surg Pathol Clin (2019) 12:921-30. doi: 10.1016/j.path.2019.08.002

2. Moniz S, Catarino AL, Marques AR, Cavaco B, Sobrinho L, Leite V. Clonal Origin of Non-Medullary Thyroid Tumours Assessed by Non-Random X-Chromosome Inactivation. Eur J Endocrinol (2002) 146:27-33. doi: 10.1530/eje.0.1460027

3. Nakazawa T, Kondo T, Tahara I, Kasai K, Inoue T, Oishi N, et al. Multicentric Occurrence of Multiple Papillary Thyroid Carcinomas-HUMARA and BRAF Mutation Analysis. Cancer Med (2015) 4:1272-80. doi: 10.1002/cam4.466

4. Lu ZM, Sheng JD, Zhang YJ, Deng JH, Li Y, Lu AP, et al. Clonality Analysis of Multifocal Papillary Thyroid Carcinoma by Using Genetic Profiles. J Pathol (2016) 239:72-83. doi: 10.1002/path.4696

5. Kuhn E, Teller L, Piana S, Rosai J, Merino MJ. Different Clonal Origin of Bilateral Papillary Thyroid Carcinoma, With a Review of the Literature. Endocr Pathol (2012) 23:101-7. doi: 10.1007/s12022-012-9202-2

6. Sun W, Lan X, Zhang H, Dong W, Wang Z, He L, et al. Risk Factors for Central Lymph Node Metastasis in CNO Papillary Thyroid Carcinoma: A Systematic Review and Meta-Analysis. PloS One (2015) 10:e139021. doi: 10.1371/journal.pone.0139021

7. Qu N, Zhang L, Wu WL, Ji QH, Lu ZW, Zhu YX, et al. Bilaterality Weighs More Than Unilateral Multifocality in Predicting Prognosis in Papillary Thyroid Cancer. Tumor Biol (2016) 37:8783-9. doi: 10.1007/s13277-015-4533-5

\section{CONCLUSIONS}

The prevalence of UMPTC is significantly lower than UUPTC despite some clinicopathological features such as age, gender, tumor size, and ETE lacking significant differences between UMPTC and UUPTC patients. However, UMPTC patients are more likely to have CLNM, LLNM, more advanced TNM stage, and recurrence/persistence than UUPTC patients. Therefore, compared with UUPTC, UMPTC patients should undergo central lymph node dissection, and pay more attention to LLNM, TNM stage and recurrence/persistence during the follow-up.

\section{DATA AVAILABILITY STATEMENT}

The raw data supporting the conclusions of this article will be made available by the authors, without undue reservation.

\section{AUTHOR CONTRIBUTIONS}

$\mathrm{HZ}$ provided the conception of the study and edited the final manuscript. TZ contributed significantly to manuscript design and preparation. TZ and WS finished clinical data collection and literature research. $\mathrm{LH}, \mathrm{ZW}, \mathrm{WD}$, and PZ analyzed the data. All authors contributed to the article and approved the submitted version.

\section{FUNDING}

This work was supported by the Scientific Research Foundation of The Education Department of Liaoning Province, China (grant no. QNZR2020009).

8. Jeong SY, Baek JH, Choi YJ, Lee JH. Ethanol and Thermal Ablation for Malignant Thyroid Tumours. Int J Hyperthermia (2017) 33(8):938-45. doi: 10.1080/02656736.2017.1361048

9. Sakai T, Sugitani I, Ebina A, Fukuoka O, Toda K, Mitani H, et al. Active Surveillance for T1bN0M0 Papillary Thyroid Carcinoma. Thyroid (2019) 29:59-63. doi: 10.1089/thy.2018.0462

10. Haugen BR, Alexander EK, Bible KC, Doherty GM, Mandel SJ, Nikiforov YE, et al. 2015 American Thyroid Association Management Guidelines for Adult Patients With Thyroid Nodules and Differentiated Thyroid Cancer. Thyroid (2016) 26:1-133. doi: 10.1089/thy.2015.0020

11. Haddad RI, Nasr C, Bischoff L, Busaidy NL, Byrd D, Callender G, et al. NCCN Guidelines Insights: Thyroid Carcinoma, Version 2.2018. J Natl Compr Canc Netw (2018) 16:1429-40. doi: 10.6004/jnccn.2018.0089

12. Veyseller B, Yenigun A, Aksoy F, Meric A, Ozturan O. The Need for Completion Thyroidectomy in Cases of Differentiated Thyroid Cancer. Indian J Otolaryngol Head Neck Surg (2019) 71:82-7. doi: 10.1007/s12070-017-1083-8

13. Calo G, Erdas E, Medas F, Gordini L, Longheu A, Pisano G, et al. Differentiated Thyroid Cancer: Feasibility of Loboisthmectomy in an Endemic Region. Il Giornale di chirurgia (2015) 36:257-62. doi: 10.11138/ gchir/2015.36.6.257

14. Xiang T, Yan W, Zhou L. Retrospective Analysis of Prognostic Factors in Patients of Papillary Thyroid Microcarcinoma. Oncotarget (2018) 9:35553-8. doi: 10.18632/oncotarget.26248 
15. Liberati A, Altman DG, Tetzlaff J, Mulrow C, Gøtzsche PC, Ioannidis JP, et al. The PRISMA Statement for Reporting Systematic Reviews and Meta-Analyses of Studies That Evaluate Health Care Interventions: Explanation and Elaboration. PloS Med (2009) 6:e1000100. doi: 10.1371/journal.pmed.1000100

16. Stang A. Critical Evaluation of the Newcastle-Ottawa Scale for the Assessment of the Quality of Nonrandomized Studies in Meta-Analyses. Eur J Epidemiol (2010) 25:603-5. doi: 10.1007/s10654-010-9491-z

17. Egger M, Davey Smith G, Schneider M, Minder C. Bias in Meta-Analysis Detected by a Simple, Graphical Test. BMJ (1997) 315:629-34. doi: 10.1136/ bmj.315.7109.629

18. Pazaitou-Panayiotou K, Alevizaki M, Boudina M, Drimonitis A, Kiziridou A, Vainas I. Cervical Masses as Manifestation of Papillary Thyroid Carcinomas $\leq 10 \mathrm{Mm}$ in Diameter, in Patients With Unknown Thyroid Disease. Thyroid Res (2009) 1:8. doi: 10.1186/1756-6614-1-8

19. Lim YC, Choi EC, Yoon YH, Kim EH, Koo BS. Central Lymph Node Metastases in Unilateral Papillary Thyroid Microcarcinoma. Br J Surg (2009) 96:253-7. doi: 10.1002/bjs.6484

20. Kim HJ, Sohn SY, Jang HW, Kim SW, Chung JH. Multifocality, But Not Bilaterality, Is a Predictor of Disease Recurrence/Persistence of Papillary Thyroid Carcinoma. World J Surg (2013) 37:376-84. doi: 10.1007/s00268-012-1835-2

21. Zhao QZ, Ming J, Liu CP, Shi L, Xu X, Nie X, et al. Multifocality and Total Tumor Diameter Predict Central Neck Lymph Node Metastases in Papillary Thyroid Microcarcinoma. Ann Surg Oncol (2013) 20:746-52. doi: 10.1245/ s10434-012-2654-2

22. Li XL, Zhao C, Hu DD, Yu Y, Gao J, Zhao WC, et al. Hemithyroidectomy Increases the Risk of Disease Recurrence in Patients With Ipsilateral Multifocal Papillary Thyroid Carcinoma. Oncol Lett (2013) 5:1412-6. doi: 10.3892/ol.2013.1202

23. Al Afif A, Williams BA, Rigby MH, Bullock MJ, Taylor SM, Trites J, et al. Multifocal Papillary Thyroid Cancer Increases the Risk of Central Lymph Node Metastasis. Thyroid (2015) 25:1008-12. doi: 10.1089/thy.2015.0130

24. Kim KJ, Kim SM, Lee YS, Chung WY, Chang HS, Park CS. Prognostic Significance of Tumor Multifocality in Papillary Thyroid Carcinoma and its Relationship With Primary Tumor Size: A Retrospective Study of 2,309 Consecutive Patients. Ann Surg Oncol (2015) 22:125-31. doi: 10.1245/ s10434-014-3899-8

25. Tam AA, Özdemir D, Çuhacı N, Başer H, Aydın C, Yazgan AK, et al. Association of Multifocality, Tumor Number, and Total Tumor Diameter With Clinicopathological Features in Papillary Thyroid Cancer. Endocr (2016) 53:7747-83. doi: 10.1007/s12020-016-0955-0

26. Wang WB, Su XY, He KF, Wang YL, Wang HY, Wang HH, et al. Comparison of the Clinicopathologic Features and Prognosis of Bilateral Versus Unilateral Multifocal Papillary Thyroid Cancer: An Updated Study With More Than 2000 Consecutive Patients. Cancer (2016) 122:198-206. doi: 10.1002/cncr.29689

27. Qu HJ, Qu XY, Hu Z, Lin Y, Wang JR, Zheng CF, et al. The Synergic Effect of BRAF(V600E) Mutation and Multifocality on Central Lymph Node Metastasis in Unilateral Papillary Thyroid Carcinoma. Endocr J (2018) 65:113-20. doi: 10.1507/endocrj.EJ17-0110

28. Kaliszewski K, Diakowska D, Wojtczak B, Migon J, Kasprzyk A, Rudnicki J. The Occurrence of and Predictive Factors for Multifocality and Bilaterality in Patients With Papillary Thyroid Microcarcinoma. Med (Baltimore) (2019) 98: e15609. doi: 10.1097/MD.0000000000015609

29. Geron Y, Benbassat C, Steinschneider M, Or K, Markus E, Hirsch D, et al. Multifocality Is Not an Independent Prognostic Factor in Papillary Thyroid Cancer: A Propensity Score-Matching Analysis. Thyroid (2019) 29:513-22. doi: $10.1089 /$ thy.2018.0547

30. Harries V, Wang LY, McGill M, Xu B, Tuttle RM, Wong RJ, et al. Should Multifocality be an Indication for Completion Thyroidectomy in Papillary Thyroid Carcinoma? Surg (2020) 167:10-7. doi: 10.1016/j.surg.2019.03.031

31. Lin XQ, Finkelstein SD, Zhu B, Silverman JF. Molecular Analysis of Multifocal Papillary Thyroid Carcinoma. J Mol Endocrinol (2008) 41:195-203. doi: 10.1677/JME-08-0063

32. Dionigi G, Kraimps JL, Schmid KW, Hermann M, Sheu-Grabellus SY, De Wailly P, et al. Minimally Invasive Follicular Thyroid Cancer (MIFTC)-A Consensus Report of the European Society of Endocrine Surgeons (ESES). Langenbeck Arch Surg (2014) 399:165-84. doi: 10.1007/s00423-013-1140-Z

33. Jovanovic L, Delahunt B, McIver B, Eberhardt NL, Bhattacharya A, Lea R, et al. Distinct Genetic Changes Characterise Multifocality and Diverse
Histological Subtypes in Papillary Thyroid Carcinoma. Pathol (2010) 42:524-33. doi: 10.3109/00313025.2010.508780

34. Gur EO, Karaisli S, Haciyanli S, Kamer E, Genc H, Atahan K, et al. Multifocality Related Factors in Papillary Thyroid Carcinoma. Asian J Surg (2019) 42:297-302. doi: 10.1016/j.asjsur.2018.05.004

35. Kaliszewski K, Strutyńska-Karpińska M, Zubkiewicz-Kucharska A, Wojtczak B, Domosławski P, Balcerzak W, et al. Should the Prevalence of Incidental Thyroid Cancer Determine the Extent of Surgery in Multinodular Goiter? PloS One (2016) 11:e0168654. doi: 10.1371/journal.pone.0168654

36. Kaliszewski K, Zubkiewicz-Kucharska A, Wojtczak B, Strutynska-Karpinska M. Multi- and Unifocal Thyroid Microcarcinoma: Are There Any Differences? Adv Clin Exp Med (2016) 25:485-92. doi: 10.17219/acem/62327

37. Dong S, Xia Q, Wu YJ. High TPOAb Levels (>1300 IU/mL) Indicate Multifocal PTC in Hashimoto's Thyroiditis Patients and Support Total Thyroidectomy. Otolaryngol Head Neck Surg (2015) 153:20-6. doi: 10.1177/ 0194599815581831

38. Zhou YL, Gao EL, Zhang W, Yang H, Guo GL, Zhang XH, et al. Factors Predictive of Papillary Thyroid Micro-Carcinoma With Bilateral Involvement and Central Lymph Node Metastasis: A Retrospective Study. World J Surg Oncol (2012) 10:67. doi: 10.1186/1477-7819-10-67

39. Zheng WH, Wang KJ, Wu JZ, Wang WD, Shang JB. Multifocality is Associated With Central Neck Lymph Node Metastases in Papillary Thyroid Microcarcinoma. Cancer Manag Res (2018) 10:1527-33. doi: 10.2147/CMAR.S163263

40. Sessa L, Lombardi CP, De Crea C, Tempera SE, Bellantone R, Raffaelli M. Risk Factors for Central Neck Lymph Node Metastases in Micro- Versus MacroClinically Node Negative Papillary Thyroid Carcinoma. World J Surg (2018) 42:623-9. doi: 10.1007/s00268-017-4390-z

41. So YK, Kim MJ, Kim S, Son YI. Lateral Lymph Node Metastasis in Papillary Thyroid Carcinoma: A Systematic Review and Meta-Analysis for Prevalence, Risk Factors, and Location. Int J Surg (2018) 50:94-103. doi: 10.1016/ j.ijsu.2017.12.029

42. Mitchell AL, Gandhi A, Scott-Coombes D, Perros P. Management of Thyroid Cancer: United Kingdom National Multidisciplinary Guidelines. J Laryngol Otol (2016) 130:S150-60. doi: 10.1017/S0022215116000578

43. Soylu L, Aydin OU, Ozbas S, Bilezikci B, Ilgan S, Gursoy A, et al. The Impact of the Multifocality and Subtypes of Papillary Thyroid Carcinoma on Central Compartment Lymph Node Metastasis. Eur Rev Med Pharmaco (2016) 20:3972-9.

44. Genpeng L, Jianyong L, Jiaying Y, Ke J, Zhihui L, Rixiang G, et al. Independent Predictors and Lymph Node Metastasis Characteristics of Multifocal Papillary Thyroid Cancer. Med (Baltimore) (2018) 97:e9619. doi: 10.1097/ MD.0000000000009619

45. Chen JY, Huang NS, Ji QH, Wang Y, Zhu YX, Li DS. Multifocal Papillary Thyroid Cancer in Children and Adolescents: 12-Year Experience in a Single Center. Gland Surg (2019) 8:507-15. doi: 10.21037/gs.2019.09.03

46. Feng JW, Pan H, Wang L, Ye J, Jiang Y, Qu Z. Total Tumor Diameter: The Neglected Value in Papillary Thyroid Microcarcinoma. J Endocrinol Invest (2020) 43:601-13. doi: 10.1007/s40618-019-01147-x

47. Connor MP, Wells D, Schmalbach CE. Variables Predictive of Bilateral Occult Papillary Microcarcinoma Following Total Thyroidectomy. Otolaryngol Head Neck Surg (2011) 144:210-5. doi: 10.1177/0194599810391616

Conflict of Interest: The authors declare that the research was conducted in the absence of any commercial or financial relationships that could be construed as a potential conflict of interest.

Publisher's Note: All claims expressed in this article are solely those of the authors and do not necessarily represent those of their affiliated organizations, or those of the publisher, the editors and the reviewers. Any product that may be evaluated in this article, or claim that may be made by its manufacturer, is not guaranteed or endorsed by the publisher.

Copyright (c) 2021 Zhang, He, Wang, Dong, Sun, Zhang and Zhang. This is an openaccess article distributed under the terms of the Creative Commons Attribution License (CC BY). The use, distribution or reproduction in other forums is permitted, provided the original author(s) and the copyright owner(s) are credited and that the original publication in this journal is cited, in accordance with accepted academic practice. No use, distribution or reproduction is permitted which does not comply with these terms. 